\title{
Duplication of the pituitary gland
}

INSERM

\section{Source}

INSERM. (1999). Orphanet: an online rare disease and orphan drug data base. Duplication of the pituitary gland. ORPHA:314621

Duplication of the pituitary gland is a rare midline cerebral malformation disorder characterized by duplicated pituitary stalks and/or glands within duplicated sella. Patients may present various degrees of facial dysmorphism and endocrine abnormalities, including precocious puberty, hypogonadism, hypothyroidism and/or hyperprolactinemia, as well as associated congenital anomalies, such as clift lip/palate, bifid nasal bridge/tongue/uvula, hypothalamic enlargement with or without hamartoma, nasopharyngeal tumors, corpus callosum ag enesis/hypoplasia, basilar artery duplication, and/or vertebral defects (in particular, duplication of the odontoid process). 